Vol. 6(6), pp. 151-157, June 2014

DOI: $10.5897 /$ JJMMS2014.1031

ISSN 2006-9723

Article Number: 836067845024

Copyright (C) 2014

International Journal of Medicine

Author(s) retain the copyright of this article

and Medical Sciences

http://www.academicjournals.org/IJMMS

\title{
Flowcytometric analysis of aldehyde dehydrogenase activity in mononuclear cells from umbilical cord blood
}

\author{
Fadia M. Attia ${ }^{1}$, Amani. A.El Baz², Mohamed abdou Abdel Naeim², Amany M. Hassan', \\ Abdel Aziz M. Mohamed ${ }^{2}$ and Magdy A. El Barbary ${ }^{2}$ \\ ${ }^{1}$ Department of Clinical Pathology, Faculty of Medicine, Suez Canal University, Egypt. \\ 'Department of Physiology, Faculty of Medicine, Suez Canal University, Egypt.
}

Received 4 March, 2009; Accepted 5 May, 2014

\begin{abstract}
Aldehyde dehydrogenase (ALDH) is a cytosolic enzyme that is responsible for the oxidation of intracellular aldehydes. Elevated levels of ALDH have been demonstrated in murine and human progenitor cells compared with other hematopoietic cells, and this is thought to be important in chemoresistance and purification techniques and an indication of the proper function of the cell. A Flowcytometric method for the assessment of ALDH activity in viable cells recently has been developed. Forty six cord blood samples from mothers which underwent normal delivery of full term infants were obtained, after informed consent. Mononuclear cells were obtained by Ficoll-Paque density centrifugation and ammonium chloride red cell lysis. Percentage of viable cells was determined by trypan blue exclusion dye. Cells were labeled with Aldefluor reagent (Vancouver Canada) as described by the manufacturer. Cells were then stained with phycoerythrin (PE)-conjugated anti-CD34 (Miltenyi Biotec, Cologne, Germany) antibodies for $30 \mathrm{~min}$ at $4^{\circ} \mathrm{C}$. Cells were washed and re-suspended in phosphate-buffered saline (PBS) with $2 \%$ fetal calf serum. Cells were then analyzed on coulter epics flow cytometer. The mean percentage of ALDH enzyme expression among the CD34+ cells in the cord blood samples was $61.3 \%$ with a minimum of $28 \%$ and a maximum of $94.6 \%$. Significant correlations were found between the white blood cell (WBCS) count in the cord blood samples and both the CD34+ cell count and the count of ALDH expressing cells, while no correlation was found between the CD34+ cells count or the ALDH expressing cells count in the cord blood samples and either the sex or the weight of the newborn. Identification and isolation of cells on the basis of ALDH activity provides a tool for their isolation and further analysis. In summary, a high ALDH-1 activity identifies CD34 ${ }^{+}$cells in cord blood.
\end{abstract}

Key words: Umbilical cord blood, stem cells, aldehyde dehydrogenase (ALDH), CD34.

\section{INTRODUCTION}

Aldehyde dehydrogenase (ALDH) is a family of enzymes involved in metabolism of aldehydes to their corresponding carboxylic acids (Cheung et al., 2007). It plays an important role in metabolism of vitamin A as well as in mechanisms of resistance to alkylating agents, for example cyclophosphamide (Storms et al., 1999). For these reasons, ALDH is considered a protecting or detoxifying enzyme, able to preserve stem cells from cytotoxic effects (Storms et al., 1999; Fallon et al., 2003; Hess et al., 2004). One of the accepted technologies to 
identify human hematopoietic stem cells (HSC) is based upon flow cytometry (FCM) detection of ALDH enzymatic activity (Storms et al., 1999).

The functional role of ALDH has been studied, with specific inhibitor of ALDH, diethylaminobenzaldehyde (DEAB), which was able to alter the molecular and cellular mechanisms that control self-renewal capacity of human HSC (Chute et al., 2006). The evidence of ALDH involvement in the physiology of HSC was further highlighted by a series of studies devoted to purification/analysis of highly immature progenitor cells, particularly in human cord blood (CB) as well as in murine bone marrow (BM) (Christ et al., 2007; Juopperi et al., 2007; Hess et al., 2006). The importance of ALDH in human hematopoiesis was also testified by a recent study in which the authors tried to purify HSCs by combining FCM cell sorting and Hoechst-33342 efflux ability (the so called "side population") (Pearce and Bonnet, 2007). At variance with previous findings obtained in mouse, human BM hematopoietic cells able to exclude Hoechst-33342 did not correspond to highly immature HSCs. On the other hand, the authors proposed that ALDH activity had to be considered as the reference method for the detection of immature HSCs in human BM, at the same time emphasizing the need for studies about expression pattern of ALDH in comparison with other hematopoietic cell markers in this tissue (Pearce and Bonnet, 2007).

Human HSCs have traditionally been characterized by the expression of cell surface markers such as CD34 (Civin et al., 1984; Bhatia et al., 1997a), but not all human hematopoietic repopulating cells express CD34 (Bhatia et al., 1998; Dao et al., 2003) and cell surface phenotype can be altered by cell cycle progression and ex vivo manipulation (Dorrell et al., 2000; Guenechea et al., 2000; Bhatia et al., 1997b; Hess et al., 2003; Nakamura et al., 1999; Sato et al., 1999). A purification strategy complementary to the use of surface phenotype involves the assessment of intracellular enzyme activities associated with the protection of primitive cells from oxidative insult during hematopoietic development. One promising purification strategy exploits cytosolic ALDH, an enzyme implicated in retinoid metabolism and the resistance of HSCs to alkylating agents such as cyclophosphamide (Sahovic et al., 1988; Takebe et al., 2001). Murine repopulating cells (Sharkis et al., 1997; Jones et al., 1995) and human hematopoietic progenitors have previously been isolated based on increased activity of intracellular ALDH (Storms et al., 1999; Jones et al., 1995).

One promising strategy is HSC isolation according to a conserved stem cell function rather than phenotype. In the murine system, lymphohematopoietic stem cells have been isolated according to the high expression of the detoxifying enzyme (ALDH) (Sharkis et al., 1997; Jones et al., 1995; Jones et al., 1995). Storms et al. (1999) described a fluorescent substrate of ALDH (termed aldefluor) that can be used to isolate cells with increased
ALDH activity by fluorescence-activated cell sorting (FACS). The substrate is an amino acetaldehyde molecule conjugated to a BODIPY (4, 4-difluoro-5,7dimethyl-4-bora-3a,4adiaza- 5-proprionic acid) fluorochrome that is metabolized by ALDH to an aminoacetate anion was retained within the cell because of its negative charge. Thus, the amount of fluorescent product that accumulates in viable cells correlates to ALDH activity and cells with high ALDH activity can be selected from human umbilical cord blood (UCB) or mobilized peripheral blood by FACS (Fallon et al., 2003; Storms et al., 1999). UCB cells isolated by using this strategy have demonstrated to be depleted of lineage committed hematopoietic cells and are enriched for primitive hematopoietic progenitors detected in clonogenic in vitro cultures (Storms et al., 1999). This approach has allowed the analysis of viable murine and human ALDH+ progenitors by flow cytometry (Storms et al., 1999).

\section{MATERIALS AND METHODS}

We obtained forty six cord blood samples from mothers attending Suez Canal University Hospital, after informed consent. All cord blood samples (each sample $=30 \mathrm{ml}$ ) were stored overnight at room temperature before ALDH analysis. The protocol was approved by the institutional research ethics committees. Mononuclear cells (MNCs) were obtained by Ficoll-Paque density centrifugation and $0.8 \%$ ammonium chloride red cell lysis. Percentage of viable cells was determined by trypan blue exclusion dye.

\section{Cell labeling}

Cells were labeled with Aldefluor reagent (Vancouver Canada) as described by the manufacturer. Cells were then stained with phycoerythrin (PE)-conjugated anti-CD34 (Miltenyi Biotec, Cologne, Germany) antibodies for $30 \mathrm{~min}$ at $4^{\circ} \mathrm{C}$. Cells were washed and re-suspended in phosphate-buffered saline (PBS) with $2 \%$ fetal calf serum. Cells were then analyzed on coulter epics flow cytometer. Aldefluor reagent was excited at $488 \mathrm{~nm}$. Gates were set up to exclude nonviable cells and debris. The negative fraction was determined using appropriate isotype controls (Figures 1 and 2). For consistent results, Aldefluor-stained cells must be analyzed within $2 \mathrm{~h}$ of labeling. However, cells retain their ability to convert the ALDH substrate for at least $24 \mathrm{~h}$ after collection. We stored cord blood samples overnight before Aldefluor labeling and analysis without any detectable effect on the ALDH profile. DEAB tubes or negative control tubes were done to confirm that cellular fluorescence was the result of the activity of cytosolic ALDH; cells were incubated with DEAB which is a specific, competitive inhibitor of cytosolic ALDH that is nontoxic to cells in vitro and in vivo for 15 $\min$ at $37^{\circ} \mathrm{C}$. These steps were repeated for each sample to be tested.

\section{Set-up analyzer}

1. In set-up mode, a DEAB control sample was placed on the cytometer; on the FSC vs. SSC plot, the R1 region was adjusted to encompass the leukocyte population of interest based on scatter. 2. On the FL1 vs. SSC plot, the FL1 photo-multiplier tube (PMT) 
Table 1. Count and percentage of CD34+ cells to the total leucocytic count (TLC) in the cord blood samples.

\begin{tabular}{lcccc}
\hline Parameter & Mean & Maximum & Minimum & Standard deviation \\
\hline \% of CD34+ cells to the TLC & 3.60 & 8.10 & 1.40 & 1.40 \\
Count of CD34+ cells $\times 103 / \mu \mathrm{l}$ & 0.48 & 1.12 & 0.12 & 0.23 \\
\hline
\end{tabular}

TLC: thin layer chromatography.

Table 2. Count of ALDHbr cells $\times 103 / \mu$ in cord blood samples.

\begin{tabular}{lcccc}
\hline Parameter & Mean & Maximum & Minimum & Standard deviation \\
\hline Count of ALDHbr cells $\times 103 / \mu \mathrm{l}$ & 0.29 & 0.89 & 0.05 & 0.19 \\
\hline
\end{tabular}

Table 3. Comparison between means of CD34+ cells count and ALDHbr cells count in cord blood samples.

\begin{tabular}{|c|c|c|c|c|c|}
\hline \multicolumn{2}{|c|}{ Cd34+cells count $\times 10^{3} / \mu \mathrm{l}$} & \multicolumn{2}{|c|}{ ALDHbr cells count $\times 10^{3} / \mu \mathrm{l}$} & \multirow{2}{*}{ t-test } & \multirow{2}{*}{$\begin{array}{c}\text { Significance } \\
\text { (2-tailed) }\end{array}$} \\
\hline Range & MESD & Range & $\mathrm{M} \pm \mathrm{SD}$ & & \\
\hline $0.12-1.16$ & $0.49 \pm 0.23$ & $0.05-0.89$ & $0.29 \pm 0.23$ & 14.07 & $0.000^{* *}$ \\
\hline
\end{tabular}

voltage was adjusted so that the right edge of the stained population was placed at the 2nd log decade on the dot plot. The tube was removed. All cells were fluorescent due to the intracellular substrate.

3. The corresponding ALDH test sample was placed on the cytometer. The $\mathrm{R} 2$ region was adjusted to encompass the cell population that was side scatter-low and ALDH-bright. The tube was removed.

4. For data acquisition of test samples, the analyzer was put in acquisition mode and 100,000 events were collected on each ALDH and $D E A B$ sample using the same instrument settings. DEAB control regions might need to be adjusted for each sample. ALDHbright, SSC-low stem cells appeared in the R2 region.

5. Analysis for double expression of ALDH bright cells and CD34 +ve cells was done.

\section{Data handling}

1. FSC vs. SSC dot plot and region $\mathrm{R} 1$ that would encompass the leukocyte population of interest based on scatter were created.

2. Two FL1 vs. SSC dot plots were created gated on R1. A region R2 was created in both plots that began at the 2nd log decade of FL1 and was within the range of $200-400$ on side scatter.

3. An ALDH positive sample data file was opened. The R1 region was adjusted in FSC vs. SSC dot plot to encompass the "viable" leukocyte population.

4. On the FL1 vs. SSC dot plot, the R2 region was adjusted to encompass the SSC low, ALDH-bright cells

5. Using the corresponding DEAB control tube, placement of the R2 region on the $A L D H$ sample was verified by making sure that there were few or no events in the R2 area.

6. Region statistics were added to the plots.

7. The percentage of the ALDH-bright population was found from the percentage gated in R2 from the FL1 vs. SSC dot plot.

\section{Statistical analysis}

Statistical package for the social sciences (SPSS version 10.0) software was used for data analysis. The Student's paired t-test for significance of no difference was used throughout this report.

\section{RESULTS}

The study population included 46 umbilical cord blood samples collected from immediate newborns, 22 males $(47.8 \%)$ and 24 females (52.2\%). The mean weight of the newborns was $3258.7 \mathrm{~g}$, with a minimum of $2,300 \mathrm{~g}$ and a maximum of $3,900 \mathrm{~g}$. The mean white blood cells count in the tested cord blood samples was $13.6 \times 10^{3} / \mu \mathrm{l}$, with a range of $5.7 \times 10^{3} / \mu \mathrm{l}$ to $27.3 \times 10^{3} / \mu \mathrm{l}$, while the mean blood hemoglobin of the tested cord blood samples was $14.5 \mathrm{~g} / \mathrm{dl}$, with a range of 10.6 to $17.2 \mathrm{~g} / \mathrm{dl}$.

The mean percentage of the CD34 cells to the total leucocytic count was $3.6 \%$; with a minimum of $1.4 \%$ and a maximum of $8.1 \%$ (Table 1); while the mean count of the CD34 cells $\times 10^{3} / \mu \mathrm{l}$ in cord blood samples was $0.48 \times$ $103 / \mu \mathrm{l}$ with a minimum of 0.12 and a maximum of $1.16 \times$ $10^{3} / \mu \mathrm{l}$ (Table 1). The mean count of the cells expressing the ALDH enzyme $\times 10^{3} / \mu \mathrm{l}$ in cord blood samples was $0.29 \times 10^{3} / \mu \mathrm{l}$, with a minimum of 0.05 and a maximum of $0.89 \times 10^{3} / \mu \mathrm{l}$ (Table 2). We found a statistically significant difference when we compared between the mean count of CD34+ cells and the mean count of ALDH expressing cells (Table 3 ). Also, there was a significant positive correlation between the count of CD34+ cells and the count of ALDH expressing cells (Figure 2). The mean percentage of ALDH enzyme expression among the CD34+ cells in the cord blood samples was $61.3 \%$ with a minimum of $28 \%$ and a maximum of $94.6 \%$ (Table 4 and Figure 3). Significant correlations were found between the WBCs count in the cord blood samples and both the 
Table 4. Percentage of ALDHbr cells to the CD34 ${ }^{+}$cells in cord blood samples.

\begin{tabular}{lcccc}
\hline Parameter & Mean & Maximum & Minimum & Standard deviation \\
\hline$\%$ of ALDHbr cells to CD34+ cells & 61.30 & 94.60 & 28 & 19.80 \\
\hline
\end{tabular}

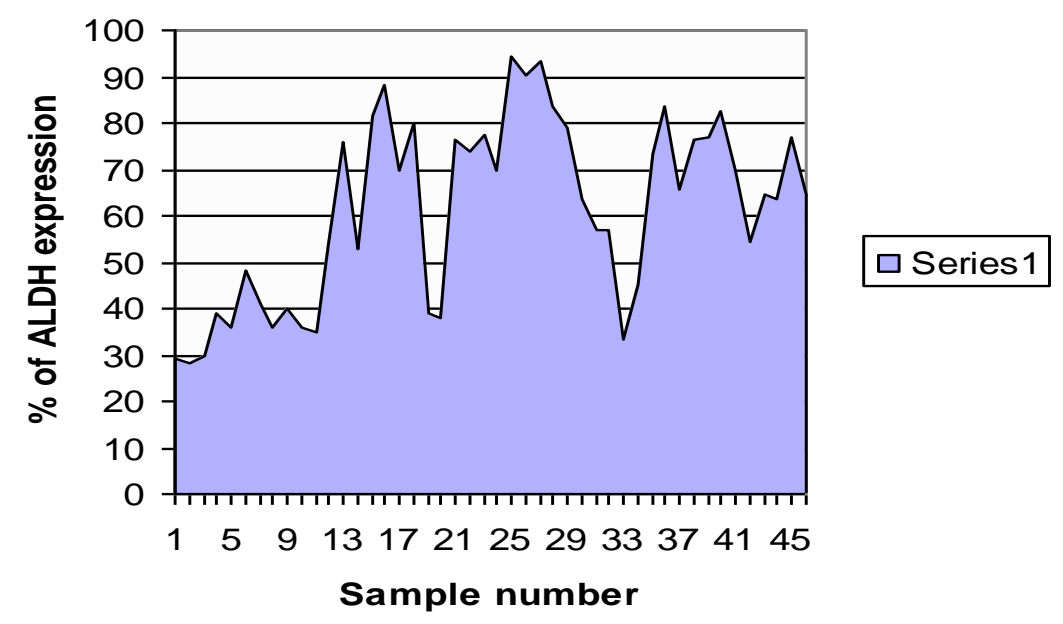

Figure 1. Percentage of ALDHbr cells to the CD34+ cells in cord blood samples

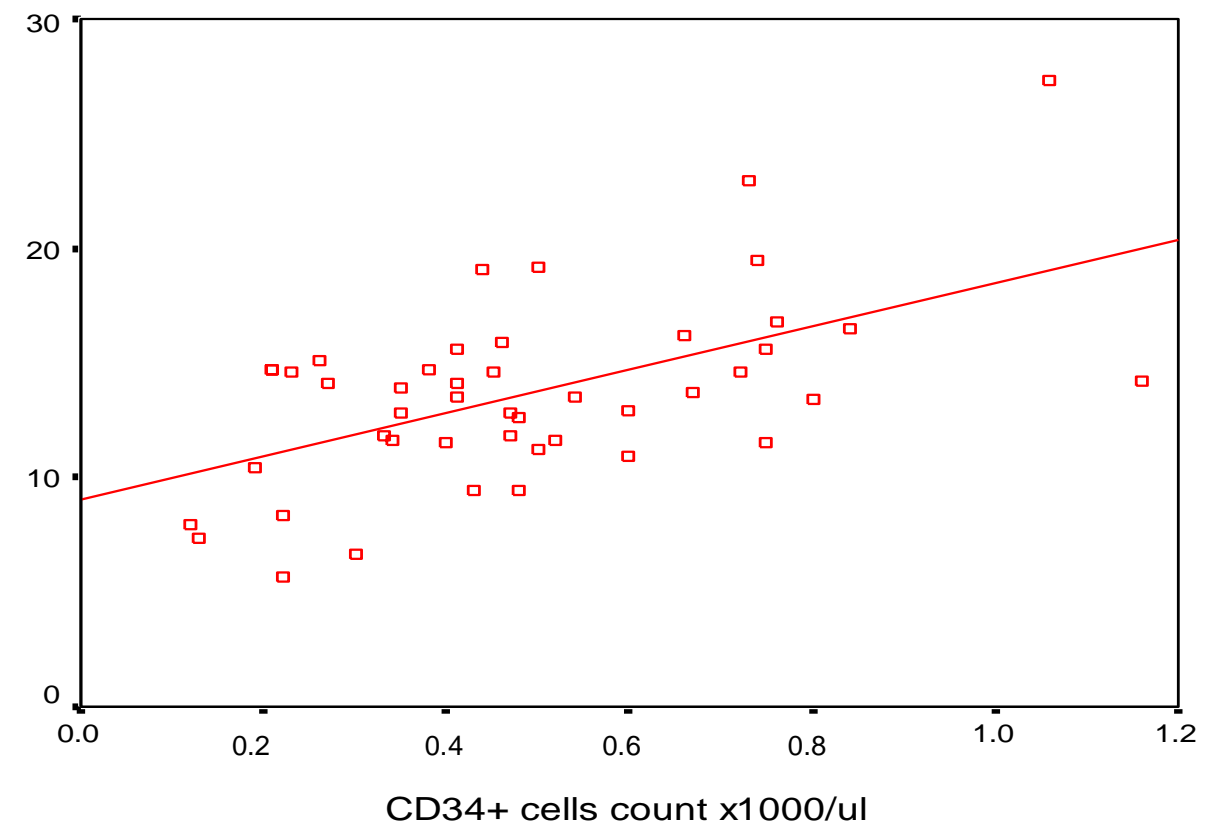

Figure 2. Correlation between WBCs count and CD34+ cells count. Pearson correlation: 0.557. Significance: 0.000 ; correlation is significant.

CD34+ cell count and the count of ALDH expressing cells (Figures 4 and 5). No correlation was found between the sexes or the weight of the newborn and neither the CD34+ cells count nor the ALDH expressing cells count in the cord blood samples.

\section{DISCUSSION}

Human cord blood hematopoietic cells with high ALDH activity are highly enriched for primitive CD34+ cells and depleted for lineage-positive (Lin+) cells (CD3, CD14, 


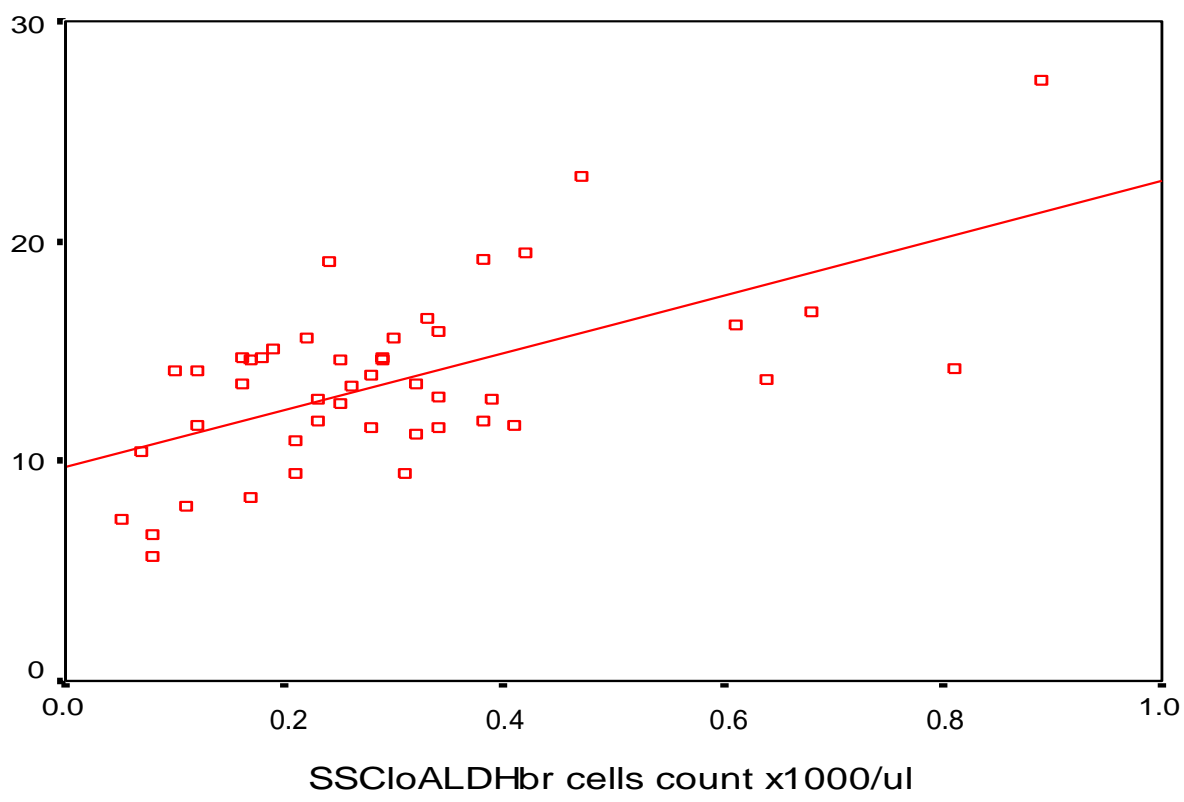

Figure 3. Correlation between WBCs count and ALDHbr cells count. Pearson correlation: 0.602 . Significance: 0.000; SSClo ALDHbr: cells with low side scatter and bright ALDH. Correlation is significant.

CD20, and CD56), indicating that they do indeed represent a primitive hematopoietic cell population (Storms et al., 1999).

Methods to safely identify primitive HSCs with enhanced repopulating function are constantly sought for clinical stem cell transplantation. Conventionally, HSCs are purified using a single isolation strategy, such as the selection of cells based on cell surface phenotype (CD34 expression) or efflux of metabolic markers such as Hoechst dye by membrane pumps (Civin et al., 1984; Bhatia et al., 1997a; Sharkis et al., 1997; Gallacher et al., 2000; Guenechea et al., 2001; De Wynter et al., 1998; Goodell et al., 1997; Handgretinger et al., 2003). However, cell phenotype, such as CD34 surface expression, can vary depending on micro-environmental factors or cellular activation (Dao et al., 2003; Hess et al., 2003) and clinical procedures are incompatible with the use of toxic or DNA-intercalating dyes. Nontoxic cell-sorting strategies based on conserved stem cell function, in combination with cell surface phenotype, are necessary for clinical cell purification and may be useful for the study of complex developmental processes such as selfrenewal versus the sequential transition from primitive HSCs to restricted progenitors. Our laboratory and others have demonstrated that cells with high intracellular ALDH activity from human UCB comprise a heterogeneous population of clonogenic progenitors and are enriched for NOD/SCID repopulating cells (Storms et al., 1999; Fallon et al., 2003; Hess et al., 2004). This isolation strategy uses a nontoxic, fluorescent substrate of ALDH, safely and effectively labeling cells with ALDH activity for selection by flow cytometry.

Many studies are describing ALDH expression in human CB (Hess et al., 2004; Christ et al., 2007; Hess et al., 2006; Gentry et al., 2007), peripheral blood stem cells (Fallon et al., 2003) and even acute myeloid leukemia (AML) BM cells (Cheung et al., 2007) data aiming to characterize normal BM ALDH+ cells are still limited to a few recent reports (Pearce and Bonnet, 2007; Gentry et al., 2007). Our interest in ALDH detection relies on the consideration that FCM based ALDH activity assessment is exploited in order to evidence a conserved stem cell function, rather than to merely identify a stem cell antigen (Morita et al., 2003).

In the current study, only $61.3 \pm 19.8 \%$ of CD34+ cells were found to express ALDH activity. Robert et al. (1999) found that $74 \% \pm 20$ of CD34+ cells express ALDH activity, while David et al. (2004) found that the percentage was $91 \pm 1.4 \%$. Christ et al. (2003) found that the percentage was $95 \pm 1 \%$. These data strongly suggest that there is functional heterogeneity within the CD34+ cell population and that further purification of human stem or progenitor cells may be achieved through the analysis of ALDH activity. ALDHbr UCB cells was found to be $2 \%$ of the thin layered chromatography (TLC) while it was about $1 \%$ in the studies done by Christ et al. (2003) and David et al. (2004).

In the current study, no relation could be found between sex or weight of the newborn and expression of ALDH or CD34+. It was reported that birth weight of the neonate did not affect the mono-nucleated cell count (MNC) and subsequently CD34+ cell count. Hiett et al. 
(1995) reported that there was no significant difference in the mean number of progenitors/UCB unit according to newborn weight. On contrary to these results, Arovita et al. (2005) reported that the correlation between birth weight and CD34+ cell concentration was statistically clearly significant. In this study, they tested $1368 \mathrm{CB}$ samples for associations of selected factors as birth weight. Another study included 3838 CB units analyzing CD34+ cell contents only on units with a volume $>80 \mathrm{ml}$, a correlation analysis of CD34+ count and weight, revealing that baby weight was associated with higher CD34+ cell content in UCB $(P=0.0001)$. In this same study, a correlation analysis of CD34+ count and sex revealed that male newborns was associated with higher content of CD34+ cells $(P=0)$ (Guenechea et al., 2000).

Arovita et al. (2005) reported also that male infants had significantly higher median CD34+ cell concentration than female infants $(31.8 \times 103 / \mu \mathrm{l}$ vs. $30.2 \times 103 / \mu \mathrm{l}$, respectively $(P=0.03)$. There are several potential applications to this strategy for identifying and isolating HSCs. Enumerating ALDHbr cells may be a more reliable means for quantitating the transplantable stem cells in bone marrow, peripheral blood and UCB. Isolating ALDHbr cells also may be an effective method for purging autologous bone marrow or peripheral blood stem cell collections of tumor cells (Colvin et al., 1999). According to the manufacturers, the Aldefluor kit is active against the ALDH-1 isoform but not the ALDH-3 isoform. Both ALDH1 and ALDH3 are reportedly involved in chemoresistance (Civin et al., 1984; Bhatia et al., 1998; Bhatia et al., 1997b). In this study, we confirmed the use of the ALDH substrate kit to identify cord blood stem/progenitor cells expressing CD 34 via multicolor flow cytometry of cord blood ALDH+ cells.

A study done by Schuurhuis et al. (2013) showed marked difference between ALDH activity of HSC and LSC with the AML BM indicating the importance of ALDH activity as a functional stem cell biomarker and its usefulness in identification and purification of HSC and LSC with the aim of treatment decision making, relapse prediction and development of LSC specific therapies. Although HSC and LSC can, in a considerable part of AML cases, be distinguished using aberrancies of marker expression (van Rhenen et al., 2007a; van Rhenen et al., 2007b; Jordan et al., 2000) and scatter properties (Terwijn et al., 2007; Janssen et al., 2011), assessment of ALDH activity enables such discrimination in all AML cases even in the absence of aberrancies.

ALDH has received considerable attention as a functional marker for identification of cells with enhanced tumorigenic/metastatic potential and elevated therapeutic resistance in several cancers of epithelial origin (Ginestier et al., 2007; Jiang et al., 2009; Tanei et al., 2009). A possible application of ALDH detection by FCM to the field of acute leukemia may derive from the study of Cheung et al. (2007), in which the authors described ALDH expression in AML. They noted that in AML patients in complete remission, a relevant population of cells characterized by high ALDH activity remained (Cheung et al., 2007). So their data about multidimensional expression profile of ALDH combined with other hematopoietic antigens in normal BM precursors could represent the basis to distinguish by FCM leukemic from normal ALDH+ cells.

Overall, the ALDH kit is quick ( $1 \mathrm{~h}$ in total), easy to use and does not significantly affect cell viability or repopulation ability. The fluorescent substrate may be analyzed in conjunction with other common fluorochromes on a standard benchtop flow cytometer equipped with a $488 \mathrm{~nm}$ laser line. These properties suggest that this is a technique more suitable for the clinic than alternative techniques that are toxic and require expensive analytical equipment (for example, a UV laser) (Goodell et al., 1997).

\section{REFERENCES}

Arovita P, Teramo K, Hiilesmaa V, Kekomaki R (2005). Cord blood hematopoietic progenitor cell concentration and infant sex. Transfusion 45(4):613-21

Bhatia M, Bonnet D, Kapp U, Wang J, Murdoch B, Dick J (1997). Quantitative analysis reveals expansion of human hematopoietic repopulating cells after short-term ex vivo culture. J. Exp. Med. 186: 619-624.

Bhatia M, Bonnet D, Murdoch B, Gan O, Dick J (1998). A newly discovered class of human hematopoietic cells with SCIDrepopulating activity. Nat Med. 4:1038-1045.

Bhatia M, Wang J, Kapp U, Bonnet D, Dick J (1997). Purification of primitive human hematopoietic cells capable of repopulating immunedeficient mice. Proc. Natl. Acad. Sci. U S A. 94:5320-5325.

Cheung A, Wan T, Leung J, Chan L, Huang H, Kwong YL, Liang R, Leung AY (2007). Aldehyde dehydrogenase activity in leukemic blasts defines a subgroup of acute myeloid leukemia with adverse prognosis and superior NOD/SCID engrafting potential. Leukemia 21(7):1423-30.

Christ O, Hamilton M, Smith C, Eaves C (2003). Short and long-term repopulating cells in human cord blood display different levels of aldehyde dehydrogenase activity as revealed by assays of Bodipystained cells in NOD/SCID mice. Blood 102:328a.

Christ O, Lucke K, Imren S, Leung K, Hamilton M, Eaves A, Smith C, Eaves C (2007). Improved purification of hematopoietic stem cells based on their elevated aldehyde dehydrogenase activity. Haematologica 92(9):1165-72.

Chute JP, Muramoto GG, Whitesides J, Colvin M, Safi R, Chao NJ, McDonnell DP (2006). Inhibition of aldehyde dehydrogenase and retinoid signaling induces the expansion of human hematopoietic stem cells. Proc. Natl. Acad. Sci. USA, 103(31):11707-12.

Civin Cl, Strauss LC, Brovall C, Fackler MJ, Schwartz JF, Shaper JH (1984). Antigenic analysis of hematopoiesis: III, a hematopoietic progenitor cell surface antigen defined by a monoclonal antibody raised against KG-1a cells. J. Immunol. 133(1):157-165

Colvin O, Thomas E, Blume K, Forman S (1999). Pharmacologic Purging of Bone Marrow. Blackwell Science; Malden, MA. Pp. $202-206$.

Dao M, Arevalo J, Nolta J (2003). Reversibility of CD34 expression on human hematopoietic stem cells that retain the capacity for secondary reconstitution. Blood 101:112-118.

David A, Meyerrose TE, Wirthlin L, Craft TP, Herrbrich PE, Creer MH, Nolta JA (2004). Functional characterization of highly purified human hematopoietic repopulating cells isolated according to aldehyde dehydrogenase activity. Blood 104(6):1648-1655.

De Wynter E, Buck D, Hart C, et al (1998). CD34+ AC133+ cells isolated from cord blood are highly enriched in long-term cultureinitiating cells, NOD/SCID-repopulating cells and dendritic cell 
progenitors. Stem Cells 16: 387-396.

Dorrell C, Gan O, Pereira D, Hawley R, Dick J (2000). Expansion of human cord blood CD34(+)CD38(-) cells in ex vivo culture during retroviral transduction without a corresponding increase in SCID repopulating cell (SRC) frequency: dissociation of SRC phenotype and function. Blood 95:102-110.

Fallon P, Gentry T, Balber AE, Boulware D, Janssen WE, Smilee R, Storms RW (2003). Mobilized peripheral blood SSClo ALDHbr cells have the phenotypic and functional properties of primitive haematopoietic cells and their number correlates with engraftment following autologous transplantation. Br. J. Haematol. 122(1):99-108.

Gallacher L, Murdoch B, Wu D, Karanu F, Keeney M, Bhatia M (2000). Isolation and characterization of human CD34(-)Lin(-) and CD34(+)Lin(-) hematopoietic stem cells using cell surface markers AC133 and CD7. Blood 95:2813-2820.

Gentry T, Foster S, Winstead L, Deibert E, Fiordalisi M, Balber AE (2007). Simultaneous isolation of human BM hematopoietic, endothelial and mesenchymal progenitor cells by flow sorting based on aldehyde dehydrogenase activity: implication for cell therapy. Cytotherapy 9(3):259-74.

Schuurhuis GJ, Meel MH, Wouters FW, Min LA, Terwijn M, de Jonge NA, Kelder A, Snel AN, Zweegman S, Ossenkoppele GJ, Smit L (2013). Normal Hematopoietic Stem Cells within the AML Bone Marrow Have a Distinct and Higher ALDH Activity Level than CoExisting Leukemic Stem Cells.8(11): e78897.

Ginestier C, Hur MH, Charafe-Jauffret E, Monville F, Dutcher J, Brown $M$, Jacquemier J, Viens $P$, Kleer CG, Liu S, Schott A, Hayes D, Birnbaum D, Wicha MS, Dontu G (2007). ALDH1 Is a Marker of Normal and Malignant Human Mammary Stem Cells and a Predictor of Poor Clinical Outcome. Stem Cell 1(5):555-567.

Goodell MA, Rosenzweig M, Kim H, Marks DF, DeMaria M, Paradis G, Grupp SA, Sieff CA, Mulligan RC, Johnson RP (1997). Dye efflux studies suggest that hematopoietic stem cells expressing low or undetectable levels of CD34 antigen exist in multiple species. Nat. Med. 3(12):1337-1345

Guenechea G, Gan O, Inamitsu T, Dorrell C, Pereira DS, Kelly M, Naldini L, Dick JE (2000). Transduction of human CD34+ CD38-bone marrow and cord blood-derived SCID-repopulating cells with thirdgeneration lentiviral vectors. Mol. Ther. 1(16):566-573.

Guenechea G, Gan OI, Dorrell C, Dick J (2001). Distinct classes of human stem cells that differ in proliferative and self-renewal potential. Nat. Immunol. 2:75-82.

Handgretinger R, Gordon PR, Leimig T, Chen X, Buhring $\mathrm{HJ}$, Niethammer D, Kuci S (2003). Biology and plasticity of CD133+ hematopoietic stem cells. Ann. N. Y. Acad. Sci. 996:141-151.

Hess D, Karanu F, Levac K, Gallacher L, Bhatia M (2003). Coculture and transplant of purified CD34(+) Lin(-) and CD34(-) Lin(-) cells reveals functional interaction between repopulating hematopoietic stem cells. Leukemia 17:1613-1625.

Hess D, Meyerrose T, Wirthlin L, Craft T, Herrbrich P, Creer M, Nolta J (2004). Functional characterization of highly purified human hematopoietic repopulating cells isolated according to aldehyde dehydrogenase activity. Blood 104(6):1648-55.

Hess D, Wirthlin L, Craft T, Herrbrich P, Hohm S, Lahey R, Eades WC, Creer MH, Nolta JA (2006). Selection based on CD133 and high aldehyde dehydrogenase activity isolates long-term reconstituting human hematopoietic stem cells. Blood 107(5):2162-9.

Hiett A, Britton K, Hague N, Brown H, Stehman F, Broxmeyer H (1995). Comparison of hematopoietic progenitor cells in human umbilical cord blood collected from neonatal infants who are small and appropriate for gestational age. Transfusion 35(7):587-91.

Janssen JJ, Deenik W, Smolders KG, van Kuijk BJ, Pouwels W, Kelder A, Cornelissen JJ, Schuurhuis GJ, Ossenkoppele G (2011). Residual normal stem cells can be detected in newly diagnosed chronic myeloid leukemia patients by a new flow cytometric approach and predict for optimal response to imatinib. Leukemia 26(5):977-84.

Jiang F, Qiu Q, Khanna A, Todd NW, Deepak J, Xing L, Wang H , Liu Z, Su Y, Stass SA, Katz RL (2009). Aldehyde Dehydrogenase 1 Is a Tumor Stem Cell-Associated Marker in Lung Cancer. Mol. Cancer Res. 7:330-338.
Jones RJ, Barber JP, Vala MS, Collector MI, Kaufmann SH, Ludeman SM, Colvin OM, Hilton J (1995). Assessment of aldehyde dehydrogenase in viable cells. Blood 85(10):2742-2746.

Jordan CT, Upchurch D, Szilvassy SJ, Guzman ML, Howard DS, Pettigrew AL, Meyerrose T, Rossi R, Grimes B, Rizzieri DA, Luger SM, Phillips GL (2000). The interleukin-3 receptor alpha chain is a unique marker for human acute myelogenous leukemia stem cells. Leukemia 14(10):1777-1784.

Juopperi T, Schuler W, Yuan X, Collector M, Dang C, Sharkis S (2007). Isolation of bone marrow-derived stem cells using density-gradient separation. Exp. Hematol. 35(2):335-41.

Morita N, Yamamoto N, Tanizawa T (2003). Correlation of c-kit expression and cell cycle regulation by transforming growth factorbeta in CD34+CD38- human bone marrow cells. Eur. J. Haematol. 71(5):351-8.

Nakamura Y, Ando K, Chargui J, Kawada H, Sato T, Tsuji T, Hotta $T$, Kato $S$ (1999). Ex vivo generation of CD34(+) cells from CD34(-) hematopoietic cells. Blood 94:4053-4059.

Pearce DJ, Bonnet D (2007). The combined use of Hoechst efflux ability and aldehyde dehydrogenase activity to identify murine and human hematopoietic stem cells. Exp. Hematol. 35(9):1437-46.

van Rhenen A, Moshaver B, Kelder A, Feller N, Nieuwint AW, Zweegman S, Ossenkoppele GJ, Schuurhuis GJ (2007). Aberrant marker expression patterns on the CD34+CD38- stem cell compartment in acute myeloid leukemia allows to distinguish the malignant from the normal stem cell compartment both at diagnosis and in remission. Leukemia 21(8):1700-1707.

van Rhenen A, van Dongen GA, Kelder A, Rombouts EJ, Feller N, Moshaver B, Stigter-van Walsum M, Zweegman S, Ossenkoppele GJ, Jan Schuurhuis G (2007). The novel AML stem cell associated antigen CLL-1 aids in discrimination between normal and leukemic stem cells. Blood, 110(7):2659-2666.

Robert W, Trujillo AP, Springer JB, Shah L, Colvin OM, Ludeman SM, Smith C (1999). Isolation of primitive human hematopoietic progenitors on the basis of aldehyde dehydrogenase activity. Proc. Natl. Acad. Sci. USA; 96(16):9118-9123.

Sahovic E, Colvin M, Hilton J, Ogawa M (1988). Role for aldehyde dehydrogenase in survival of progenitors for murine blast cell colonies after treatment with 4-hydroperoxycyclophosphamide in vitro. Cancer Res. 48:1223-1226.

Sato T, Laver J, Ogawa M (1999). Reversible expression of CD34 by murine hematopoietic stem cells. Blood 94: 2548-2554.

Sharkis S, Collector M, Barber J, Vala M, Jones R (1997). Phenotypic and functional characterization of the hematopoietic stem cell. Stem Cells 15(suppl 1): 41-45.

Storms RW, Trujillo AP, Springer JB, Shah L, Colvin OM, Ludeman SM, Smith C (1999). Isolation of primitive human hematopoietic progenitors on the basis of aldehyde dehydrogenase activity. Proc. Natl. Acad Sci. U S A. 96:9118-9123.

Takebe N, Zhao SC, Adhikari D, Mineishi S, Sadelain M, Hilton J, Colvin M, Banerjee D, Bertino JR (2001). Generation of dual resistance to 4-hydroperoxycyclophosphamide and methotrexate by retroviral transfer of the human aldehyde dehydrogenase class 1 gene and a mutated dihydrofolate reductase gene. Mol. Ther. 3:8896.

Tanei T, Morimoto K, Shimazu K, Kim SJ, Tanji Y, Taguchi T, Tamaki Y, Noguchi S (2009). Association of breast cancer stem cells identified by aldehyde dehydrogenase 1 expression with resistance to sequential paclitaxel and epirubicin-based chemotherapy for breast cancers. Clin. Cancer Res. 15:4234-4241.

Terwijn M, Rutten AP, Kelder A, Snel AN, Scholten WJ, et al (2007). Accurate detection of residual leukemic stem cells in remission bone marrow predicts relapse in acute myeloid leukemia patients. Blood ASH Annu Meet: Abstr 759. 